\title{
Competition at the ribosome exit site
}

$\begin{array}{ll}\text { NAC limits the } & \begin{array}{l}\text { During translation, nascent } \\ \text { polypeptides move through the } \\ \text { ribosome exit tunnel and emerge } \\ \text { anteraction } \\ \text { of SRP with }\end{array} \\ \text { the ribosome } & \begin{array}{l}\text { with factors that co-translationally } \\ \text { regulate their processing, folding } \\ \text { and subcellular targeting. These } \\ \text { factors include the methionine } \\ \text { and with }\end{array} \\ \text { nascent chains } & \begin{array}{l}\text { aminopeptidase (MetAP), which } \\ \text { removes the amino-terminal methio- } \\ \text { nine (the first residue incorporated } \\ \text { the cytosol }\end{array} \\ \begin{array}{l}\text { into all nascent chains) from the } \\ \text { majority of proteins destined for } \\ \text { the cytosol; the signal recognition } \\ \text { particle (SRP), a ribonucleoprotein } \\ \text { composed of six proteins and the SRP } \\ \text { RNA, which recognizes secretory and } \\ \text { membrane proteins and targets them } \\ \text { to the endoplasmic reticulum; and } \\ \text { the nascent polypeptide-associated }\end{array}\end{array}$

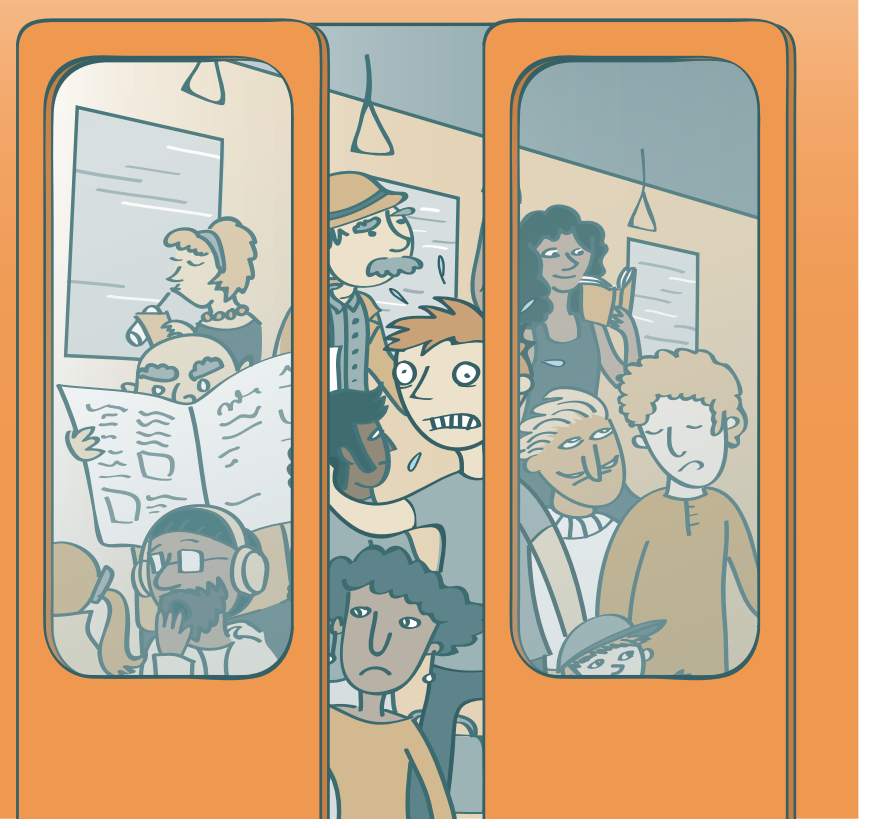

Lara Crow/NPG complex (NAC), which is thought to deliver nascent chains to the SRP as well as to prevent the interaction between non-secretory chains and the translocation machinery.

How the binding of MetAP, SRP and NAC (which may compete for the same ribosomal site) to ribosomes is regulated remains unclear. Nyathi and Pool report that binding of the NAC at the ribosome exit site determines whether MetAP or SRP bind, thus influencing the fate of the nascent chain.

First, the authors observed that Map1, which is the main yeast isoform of MetAP, associated in vivo with the ribosomal proteins Rpl25 and Rpl35 (also known as uL23 and uL29, respectively), which are recognized as the 'universal adaptor site' (UAS), because they bind to several nascent chain-binding factors, including the SRP. Map1 was shown to bind directly to UAS; this binding was lost and Map1 activity was reduced to $\sim 50 \%$ in a yeast strain expressing a version of Rpl25 that cannot bind to SRP.

In yeast, NAC is predominantly found as an $\alpha$ NAC- $\beta$ NAC heterodimer. Analysis of cross-linking products revealed that $\alpha \mathrm{NAC}$ binds to the UAS, and that Map1 and aNAC can simultaneously bind to the ribosome at adjacent sites on the UAS.

Therefore, Map1, NAC and the SRP can interact with the ribosome at the UAS. The authors found that overexpression of Map1 reduced SRP-ribosome binding, whereas overexpression of SRP increased SRP-ribosome binding while reducing Map1-ribosome binding, but only in yeast depleted of NAC. Moreover, SRP association with the ribosome in the absence of NAC interfered with the biogenesis of cytosolic proteins, leading to protein aggregation. These observations indicate that SRP antagonizes Map1ribosome binding, and that NAC limits the interaction of SRP with the ribosome and with nascent chains destined for the cytosol.

In summary, methionine processing by Map1 is facilitated by NAC occupying an adjacent site on the ribosome, as NAC limits the antagonistic function of SRP. Previous observations have indicated that secretory proteins first contact $\mathrm{NAC}$ and then SRP, and that NAC is involved in the handover of secretory chains to SRP in vitro. Nyathi and Pool suggest that NAC 'samples' nascent chains: NAC binding to nascent cytosolic chains facilitates Map1 function, whereas the presence of a signal sequence may lead to conformational rearrangements of NAC and/or ribosomes that favour SRP interactions and handover of nascent chains to SRP. Interestingly, the authors also found that NAC helps to prevent aggregation of SRP substrates before translocation.

Kim Baumann

ORIGINAL RESEARCH PAPER Nyathi, Y. \& Pool, M. R. Analysis of the interplay of protein biogenesis factors at the ribosome exit site reveals a new role for NAC. J. Cell Biol. 210, 287-301 (2015) 